\title{
The Teaching of Fractions - Emerging Questions from the Combined Reading of Brazilian and Canadian Curricular Documents
}

\author{
Priscila Dias Corrêa ${ }^{1}$, Leticia Rangel ${ }^{2}$ \\ ${ }^{1}$ University of Windsor, Canada \\ ${ }^{2}$ Universidade Federal do Rio de Janeiro, Brazil
}

\begin{abstract}
To contribute to the reflective process inherent to the teaching practice and to the development of knowledge of mathematics for teaching, this article analyzes curriculum documents from two different countries and offers some questions for discussion. The focus of the study is on the teaching of numbers and the analysis emphasizes fractions. The article is based on an analytical study on the teaching of numbers based on the combined reading of official curricula from Brazil and Canada. It contributes to establishing a methodology of relational analysis among curricular documents. The study offers a visual model, the curricular trajectory, which points out parities and contrasts grounded on the identification of elementary aspects revealed in the structuring elements of both curricula. Based on the curricular trajectory, this paper poses questions of fundamental relevance to the teaching of fractions.
\end{abstract}

\section{Introduction}

In light of recurrent discussions about the mathematics curriculum around the world [1] [2], this study presents an analytical investigation on the teaching of numbers, from grades 1 to 6 of elementary education. In particular, the investigation emphasizes the teaching of fractions. To this end, curricular documents from Brazil and Canada are analyzed. $\mathrm{Li}$ and Lappan [1] argue that the "[1] earning and sharing of mathematics curriculum and its changes in different education systems should provide us with a unique lens to advance curriculum research and practice from an international perspective" (p.4). The aim of this study is not to compare the teaching of numbers in Brazil and Canada to point out which country has the "best" curricular choices. We understand that each country has its peculiarities and that for different reasons what is appropriate for one country is not necessarily suitable for another. We do not believe in universal curriculum guidelines. We acknowledge the value and the impact of social, cultural, and economic aspects in the teaching of mathematics, but we do not consider these aspects in this study. We assume that the curricular documents exist and have a central role in the teaching practice of each country.

The reflection proposed in this paper aims to inform the development of curricular sequences as well as teachers' practice in what concerns numbers, in particular fractions, contributing to the development of mathematical knowledge for teaching, as defined by Ball [3]. Teachers can perceive aspects related to the teaching of fractions that could not be noticed in the direct implementation of a curriculum. The analysis of a curriculum, grounded on another curriculum, draws attention to equivalences, similarities and differences that may potentially aid the promotion of a critical and enhanced teaching of numbers. Therefore, this research investigates the question: How does an analytical study, based on the curricular documents from Brazil and Canada, contribute to the reflection on the teaching of numbers, in particular on the teaching of fractions?

\section{Curricula}

Official documents that describe and discuss the mathematics that should be taught in school education are often called curriculum. The UNESCO glossary [4] recognizes that there is a variety of possible definitions for curriculum and argues that "the curriculum is not an end in itself but rather a means to fostering quality learning" (p.16). The glossary defines curriculum as "a description of what, why, how and how well students should learn in a systematic and intentional way" (p.16).

A curriculum plays a central role in education systems; it serves as a guide and support for teachers. Hence, a curriculum can be the starting point for investigating the teaching of mathematics [1] [2]. Two curricular documents are used for this research: the Brazilian National Common Curricular Framework BNCC [5], of national extent, and the Common Curriculum Framework - CCF [6], of regional extent, directed to the provinces and territories in the west and north of Canada.

Several issues involve curriculum design. In addition to the central question about what content should be included in the curriculum and in what sequence, there are other relevant questions to be answered. For example: How does a curriculum relate to public education policies? How does a curriculum address cultural diversity? What does a curriculum reveal about the role of schools and teachers? What determines if a content is a curricular content or not? 
Several authors investigate these and other related issues [7] [8] [9] [10] [11]. We do not discuss these issues in this research, even though we recognize their relevance. This study is grounded on the mathematical content sequence across school years.

The implementation of a curriculum involves several factors related, for example, to schools' pedagogical project, teachers' practice, teaching methods, available resources, and students involved. The implementation also involves the interpretation and level of depth of the curriculum and methodological choices. Ted Aoki [12] described this tension between the planned and the lived curriculum. This discussion on the different dimensions of a curriculum has evolved in the last decades and, currently, it is possible to distinguish between at least the intended, the implemented, and the learned curriculum [1] [4] [13]. The focus of this study is specific: the curriculum distribution of mathematics content in official curriculum documents, that is, the intended curriculum. Therefore, we do not explore aspects of the implemented curriculum, such as classroom practice and textbooks, nor aspects of the learned curriculum. The learning itself is not the object of this study. On the other hand, this study involves the interpretation and the analysis of curricular documents, essential steps for the transformation of the intended curriculum into the implemented curriculum. We endorse that the intended and the implemented curricula are not conflicting, but complementary. We offer a reflection that supports the decision-making of mathematics teachers when implementing a curriculum.

\section{BNCC and CCF}

The BNCC [5] is a recent document that has the potential to portray current trends in the teaching of mathematics in Brazil. In contrast, the CCF [6], an older document, offers a consolidated perspective. The documents have similar structures, both based on grades. They offer relevant material for analysis, providing an opportunity to discuss and reflect on the teaching of mathematics. We claim that comparative analysis that highlights parities and contrasts can contribute to the discussion of the curriculum in the context of mathematics education (e.g. [14]).

The BNCC is the fundamental reference for the creation of local and regional curricula in school systems in Brazil. Such curricula must integrate social, cultural, and methodological features into the normative document, without disrespecting the progressive set of learning outcomes designed for each school year and depicted in the BNCC. In what concerns mathematics education, the BNCC states its commitment to the development of mathematical literacy (as defined in [15]) throughout elementary education (grades 1 to 9). In the BNCC, equivalence, proportionality, interdependence, representation, order, variation, and approximation constitute a set of fundamental ideas that promote the articulation between the fields of mathematics - Arithmetic, Algebra, Geometry, Statistics and Probability. These different fields and the fundamental ideas determine five strands in the Brazilian curriculum framework: Numbers, Algebra, Greatness and Measurement, Geometry and Statistics and Probability. For each strand and grade level, knowledge topics (consisting of content, concepts, and processes) and their respective skills are defined. These skills represent the essential learning that must be achieved by students.

The CCF comprises a curriculum framework adopted by seven of the ten provinces and by the three territories in Canada [16]. The document is organized around four strands: Number, Patterns and Relations, Shape and Space, and Statistics and Probability. Each strand has general outcomes. Guided by them, specific outcomes are defined, that is "specific skills, understanding and knowledge students are required to attain by the end of a given grade" [6] (p.13). For each specific outcome, the CCF establishes a series of achievement indicators. These indicators illustrate what can be expected from students concerning the learning of each of the curricular goals. They are beacons that can serve as a basis for the teacher, helping to elucidate what each of the specific outcomes refers to. Two concepts guide the distribution and outlining of specific outcomes and achievement indicators in the CCF: the nature of mathematics and the mathematical processes. The nature of mathematics is explained by the identification of intrinsic components: change, constancy, number sense, patterns, relationships, spatial sense, and uncertainty. While the mathematical processes are communication, connections, mental mathematics, and estimation, problem-solving, reasoning, technology, and visualization.

Both documents focus on learning and not on teaching. This can be observed in the writing of the skills in the BNCC and the specific outcomes in the $\mathrm{CCF}$. The verbs that are used point to what the student is expected to learn, and not to what the teacher is expected to teach. The curricular frameworks of the two documents are organized based on what we identify as structuring elements: the knowledge topics and skills in the BNCC, and the specific outcomes and achievement indicators in the CCF (see Table 1).

\section{The Research Study}

This study aims to investigate and discuss the guidelines for the teaching of numbers, in particular for the teaching of fractions, in official curricular documents from Brazil and Canada. The research investigates the mathematical content, related to numbers, covered in school for students aged 6 to 11 years old, that is, the first six years of elementary education. Why numbers? Numbers usually mark the 
first contact with mathematics. Also, we agree with Kilpatrick and colleagues [17] in that

proficiency with numbers and numerical operations is an important foundation for further education in mathematics and in fields that use mathematics. ... the domain of number both supports and is supported by other branches of mathematics, including algebra, measure, space, data, and chance. Our decision to address the domain of number was a pragmatic one; in no way does it imply that the elementary and middle school curriculum should be limited to arithmetic. (p. 2)

Table 1. Structuring elements

\begin{tabular}{|c|c|}
\hline $\begin{array}{c}\text { BNCC } \\
\text { [5] } \\
\text { Grade } 2 \\
\text { (p. 283) }\end{array}$ & $\begin{array}{l}\text { Knowledge Topics: } \\
\text { Reading, writing, comparing and ordering } \\
\text { numbers up to hundreds by understanding } \\
\text { the features of the decimal number system } \\
\text { (place value and the role of the number zero). } \\
\text { Skills: } \\
\text { (EF02MA01) Compare and order natural } \\
\text { numbers (up to hundreds) by understanding } \\
\text { the characteristics of the decimal number } \\
\text { system (place value and the function of the } \\
\text { zero). }\end{array}$ \\
\hline $\begin{array}{c}\text { CCF } \\
\text { [6] } \\
\text { Grade } 2 \\
\text { (p. 64) }\end{array}$ & $\begin{array}{l}\text { Specific Outcomes: } \\
\text { 5) Compare and order numbers up to } 100 \text {. } \\
\text { Achievement Indicators: } \\
\text { Order a given set of numbers in ascending or } \\
\text { descending order and verify the result using } \\
\text { a hundred chart, number line, ten frames or } \\
\text { by making references to place value. } \\
\checkmark \quad \text { Identify errors in a given ordered } \\
\text { sequence. } \\
\checkmark \quad \text { Identify missing numbers in a given } \\
\quad \text { hundred chart. } \\
\checkmark \text { Identify errors in a given hundred chart. }\end{array}$ \\
\hline
\end{tabular}

The structuring elements of the curricular frameworks in the BNCC and the CCF are considered for this research. As a result of the study, a visual multidimensional resource, which highlights parities and contrasts between the two documents progressively over the schooling years, was designed: the curricular trajectory. This resource offers, in a schematic way, a combined view of the sequential organization of the teaching of numbers according to the curricular guidelines of these two countries. We believe that the (proposed) design of the curricular trajectory - which allows us to read beyond the parities and contrasts between the analyzed frameworks - can contribute to studies about curriculum. As devised, the curricular trajectory can serve as a reference for comparisons between the analyzed documents and other curricular documents, can be extended by including other curricular distributions, and can be adapted to contemplate additional content other than numbers.

A qualitative approach grounded on the document analysis of the BNCC and the CCF was used as the research methodology. According to Sharma [18], document analysis is a research methodology that is based on original or primary publications to answer a research question. This study collects data from the indicated documents, performs a qualitative analysis of the data, and proposes a curricular trajectory and reflections on the teaching of numbers from grade 1 to grade 6 . This period marks the initial identification of mathematics as a curricular component and offers a natural match between the chronological ages of students in Brazil and Canada. The methodology used, despite considering the school years, does not focus on a fragmented reflection limited to these years separately, but rather on the chain of conceptual construction revealed in the documents. The aim is to highlight the sequential order of the content and the time set to approach them, and not necessarily the school year(s) in which the content is taught.

The qualitative nature of the methodology shaped a dynamic analysis that led to the identification of four interdependent emphases, with no tiered relationship between them: (i) panorama - characterized by a combined reading of the documents; (ii) elementary aspects - characterized by the identification of elementary aspects in the teaching of numbers; (iii) parities and contrasts - characterized by the identification of equivalences, similarities and differences between the structuring elements of the documents; and (iv) curricular trajectory characterized by the mapping of the two curricular proposals (see Figure 1).

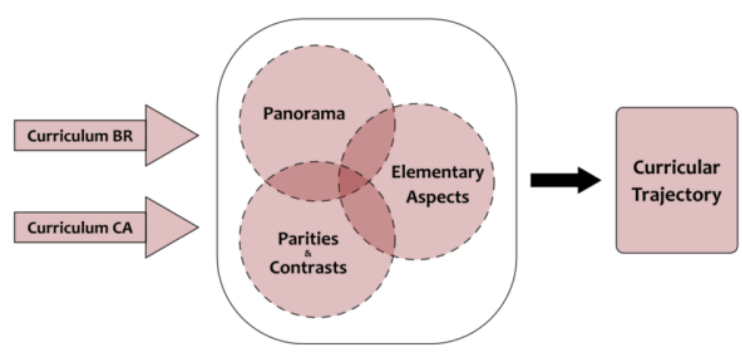

Figure 1. Methodological process

The combined reading of the two curricular documents was the starting point of the analysis, and the panorama emphasis characterized the beginning of this process. According to Zanette [19], in qualitative research, "the researcher is constantly faced with the need to know and discuss the path to be followed in order to figure how to transform the investigation phenomenon into a research object" (p.150). The need for categories of analysis yielded two other emphases: parities and contrasts and elementary aspects. Although the four emphases had different focuses, the processes of analysis and 
construction of the curricular trajectory were characterized by the overlap of the emphases, notably of the first three emphases. The emphasis curricular trajectory is of a conclusive nature.

\subsection{Panorama}

The panorama emphasis is marked by a combined reading of the documents aimed at obtaining a general perspective of each of the curricular documents regarding the conceptual construction of numbers. This stage of the analysis was initially characterized by the arrangement of the structuring elements of each document (knowledge topics and skills in the BNCC and specific outcomes and achievement indicators in the $\mathrm{CCF}$ ). We observed that the analysis should accommodate equivalences, similarities, and differences. For example, looking at Table 1, for grade 2 , we have "compare and order natural numbers (up to hundreds) by understanding the characteristics of the decimal number system (place value and the function of the zero)" as a skill in the BNCC and "compare and order numbers up to 100 " as a specific outcome in the CCF. The prompt to consider up to hundreds in the Brazilian curriculum, or up to tens (maximum 100) in the Canadian curriculum, characterize a difference in the structuring elements However, there is a relationship between them, both refer to the comparison and ordering of natural numbers. Another example (in which there is no possible correspondence) is observed when the CCF includes integer numbers in grade 6 , a content that is not included in the BNCC before grade 7. Due to the often lack of correspondence or full equivalence in the panorama emphasis, it was raised the need for two categories of analysis: one that distinguished elementary aspects in the structuring elements, and another one that observed parities and contrasts between the structuring elements.

\subsection{Elementary aspects}

Klein identified as elementary mathematics the essential parts that support and structure mathematics [20] [21]. Based on Klein's understanding, elementary mathematics is not the same as simplified mathematics, nor does it refer to simple or easy mathematics. The concept of number is a good example: it involves abstraction, biunivocal correspondence, unity and representation, in addition to properties and characteristics that determine the different numerical universes. The history of the concept of number reveals that it is not an easy thing, nor it can be facilitated. However, no one denies its elementary value for mathematics in Klein's sense.

Grounded on Klein's work, elementary aspects are defined as concepts and understandings that support the learning of a subject. For example, when learning about whole numbers, comparison and ordering are elementary aspects that were identified in the two documents. Another elementary aspect of whole numbers is representation, which can be noticed, for example, when the BNCC suggests that grasping the attributes of the decimal number system underpins comparison and ordering. When distinguishing elementary aspects, prominence was given to the content and its sequential distribution, and not to specific details in the structuring elements. That is the case, for instance, when distinguishing comparison and ordering as elementary aspects and not distinguishing the limitation of the numbers involved as indicated in Table 1.

The elementary aspects that emerged in this study do not exhaust the elementary aspects that could be considered in the teaching of numbers. We do not intend to propose a basic list of elementary aspects on the theme, but to draw attention to those evidenced in the documents according to our analysis.

\subsection{Parities and contrasts}

This emphasis sought to identify equivalences or similarities and differences in the structuring elements of the two curricular documents. In this process, parities and contrasts are highlighted.

Parities emerge from structuring elements that correspond to the same content, or that have great similarity, and are taught in the same school year. For example, the beginning of the teaching approach about whole numbers in grade 1 based on counting, comparison, representation, and the number line, is a parity. Another parity that emerges from the combined reading of the documents is observed in grade 5 when the notion of equivalent fractions is introduced. This content is portrayed as a BNCC skill - "identify equivalent fractions [emphasis added]" [5] (p. 295), and as a specific outcome in the CCF "create sets of equivalent fractions [emphasis added]" [6] (p.99). Parities can also be observed based on the absence. For example, none of the documents proposes the teaching of multiplication and division of fractions before grade 7 .

On the other hand, contrasts are identified based on structuring elements that reveal differences in content or approaches or that, despite corresponding to the same content and approach, are taught in different school years. For example, the Canadian curricular guidelines propose the teaching of percentages starting from grade 6 , while the Brazilian guidelines determine that this same content should be taught from grade 5. Another contrast that emerges from the combined reading is the fact that the Canadian document proposes the teaching of negative numbers in grade 6 , a content that does not appear in the Brazilian document before grade 7 .

Parities and contrasts are not mutually exclusive. A closer examination of a parity may reveal a contrast, and a contrast can hide a parity. For 
example, the multiplication of whole numbers appears as a knowledge topic in the BNCC starting in grade 2. The multiplication of whole numbers is also the focus of a specific outcome in the CCF, and it appears for the first time in grade 3 . We identified that multiplication is an elementary aspect of the teaching of whole numbers present in both documents and that both start limiting multiplication factors to numbers less than or equal to 5 , therefore a parity. The beginning of the approach in different school years, on the other hand, shows a contrast. Another example refers to the teaching of rational numbers represented in decimal expansion. Both curricular documents propose the beginning of this content at the fourth school year, the year that follows the introduction of fractions. This characterizes a parity. However, if we look more closely at the structuring elements of these documents, the Canadian orientation is more comprehensive than the Brazilian, which recommends that this content be taught within a monetary context (see Table 2).

Table 2. Structuring elements - rational numbers represented on decimal expansion

\begin{tabular}{|c|l|}
\hline $\begin{array}{c}\text { BNCC } \\
\text { [5] }\end{array}$ & $\begin{array}{l}\text { Skill: } \\
\text { (EF04MA10) Recognize that the rules of the } \\
\text { decimal numbering system can be extended } \\
\text { to the decimal representation of a rational } \\
\text { number and relate tenths and hundredths } \\
\text { with the representation of the Brazilian } \\
\text { monetary system. }\end{array}$ \\
(p. 291) \\
\hline $\begin{array}{c}\text { CCF } \\
\text { [6] }\end{array}$ & $\begin{array}{l}\text { Specific Outcome: } \\
\text { and hundredths), concretely, pictorially and } \\
\text { symbolically. }\end{array}$ \\
Grade 4 & $\begin{array}{l}\text { 10) Relate decimals to fractions (to } \\
\text { hundredths). }\end{array}$ \\
(p. 89)
\end{tabular}

We understand that the value of recognizing parities and contrasts lies in the critical-reflective process of identifying them and not in the categorization itself. Refining or extending the discussion on parities and contrasts is a legitimate and natural process, a result of this study.

\subsection{Curricular trajectory}

The curricular trajectory (see Figure 2) is a graphic resource that portrays the conclusive aspects of this study analysis. Its visual nature combines and integrates the three emphases, offering a panorama that presents the elementary aspects of the documents, and highlights parities and contrasts. The curricular trajectory, a four-dimensional infographic, consists of (i) temporal variation, marked by the grade sequence on the horizontal axis, (ii) number sets (whole, rational and integer), distributed vertically and differentiated by colours, (iii) elementary aspects that emerged from the study analysis and are indicated in the central part of the Cartesian system, and (iv) country of origin, identified by its respective flags.

The curricular trajectory indicates the beginning and the duration of the teaching processes of the elementary aspects, without attending to details. For example, it is observed in the curricular trajectory that both the BNCC and the CCF address the addition and subtraction of whole numbers from grade 1 to 6 . However, the curricular trajectory does not specify what is explored in each grade. In the multiplication and division of whole numbers, a parity is observed once both documents address the topic from grade 3 to 6. Still, the BNCC explores the multiplication of whole numbers as early as grade 2, revealing a contrast. The curricular trajectory unveils the parities and contrasts but does not indicate what exactly is addressed about the multiplication of whole numbers in grade 2 of the Brazilian document.

The creation of the curricular trajectory required analysis. The arrangement of rational numbers based on fractions, decimals and percentage is an example. The decision to distribute and categorize the data according to such topics was a necessity that emerged from the construction of the curricular trajectory. Fractions, decimals, and percentage have their own paths in the development of the concept of rational numbers, that is until the necessary abstraction is achieved. This separation allowed us to observe, for example, that both countries begin to approach rational numbers as fractions in grade 3 and that both start exploring the decimal representation of rational numbers in the following grade. In addition, the BNCC includes powers of rational numbers as decimals in grade 6 , which is not the case for the CCF. On the other hand, it can be noticed that powers of rational numbers as fractions are not included in the Brazilian curricular guidelines up until the end of grade 6, which is in tune with the fact that the multiplication of fractions is also not mentioned.

It should be noted that contrasts such as the study of powers, an elementary aspect identified in only one of the documents, are highlighted in the curricular trajectory in red. The same visual aid is used, for example, to highlight the representation, comparison and ordering of integer numbers, elementary aspects observed only in the Canadian document. 


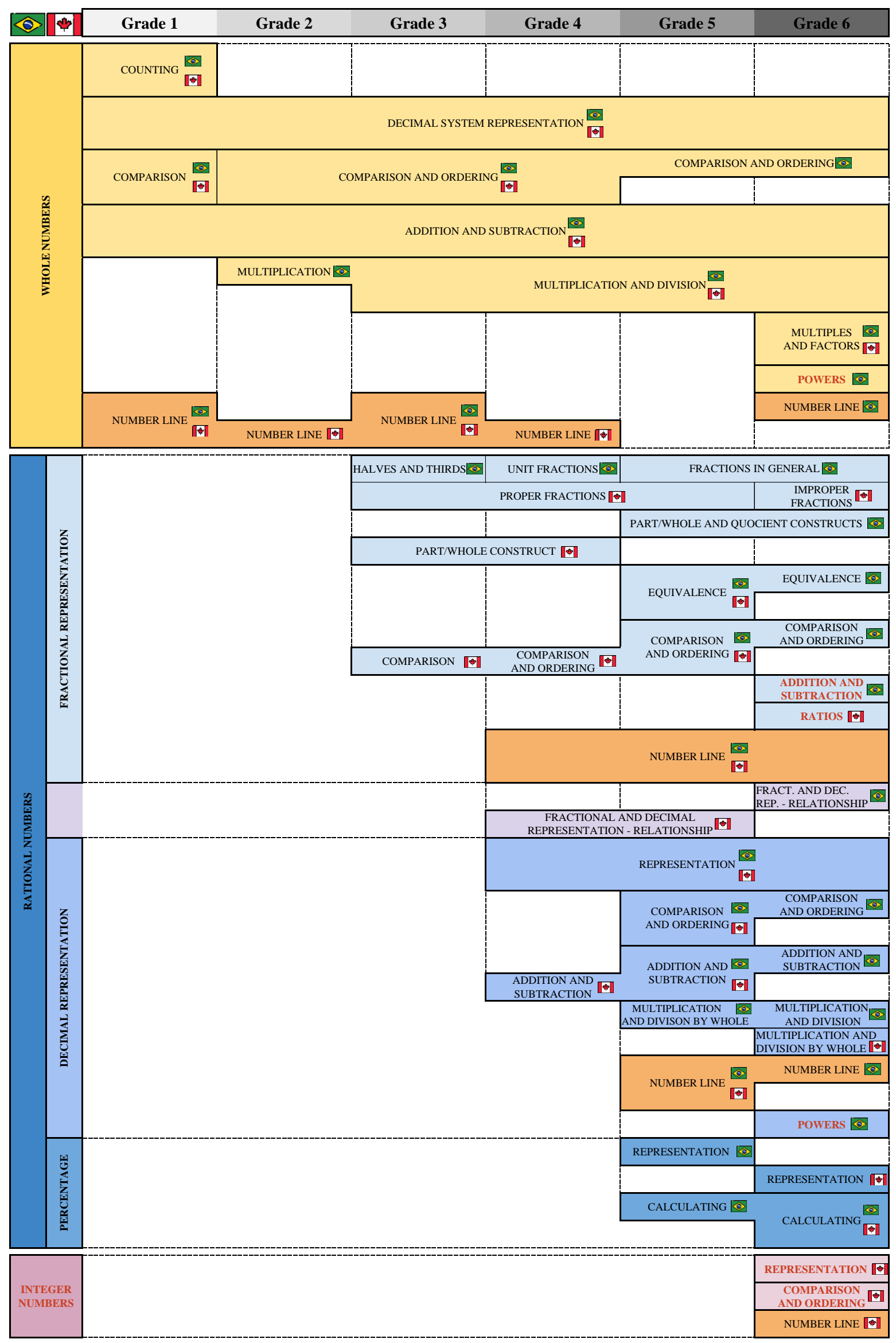

Figure 2. Curricular trajectory (numbers, grades 1 to 6 ) 


\section{The curricular trajectory and teacher's practice: the teaching of fractions}

One of the goals of analyzing school mathematics curricula based on curricular documents from different countries is to promote reflection on teaching processes and contribute to teachers' practice. Ultimately, the aim is to contribute to students' mathematics learning. With this goal in mind, this study provides mathematics teachers with a visual tool, the curricular trajectory, which draws attention to content- and teaching-related aspects of mathematics education. As a result, teachers can question, analyze, and evaluate different teaching proposals related to the same mathematical content. We understand that this is an exercise that contributes to the development of teachers' own knowledge, the knowledge of mathematics for teaching ([3], see Figure 3). The knowledge about the curriculum is an integral part of the knowledge of mathematics for teaching ([3] [22]).

By "mathematical knowledge for teaching," we mean the mathematical knowledge needed to carry out the work of teaching mathematics. Important to note here is that our definition begins with teaching, not teachers. It is concerned with the tasks involved in teaching and the mathematical demands of these tasks. Because teaching involves showing students how to solve problems, answering students' questions, and checking students' work, it demands an understanding of the content of the school curriculum. [3] (p.21)

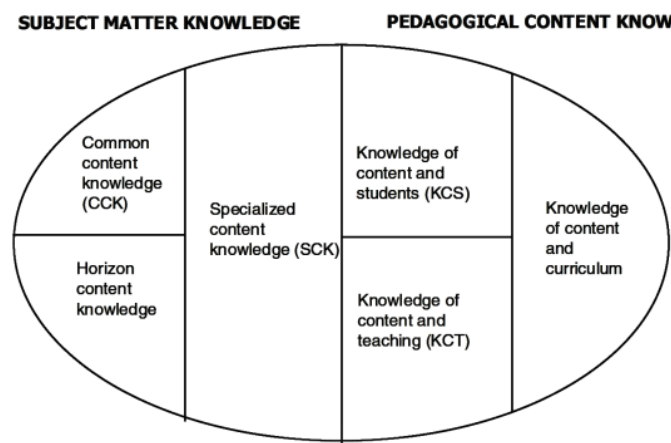

Figure 3. Domains of mathematical knowledge for teaching [3] (p. 403)

To exemplify a few possibilities for reflection, provided by the curricular trajectory, we can look at rational numbers. The study of rational numbers can be investigated starting from the introduction to fractions until the study of percentages. The curricular trajectory suggests that the initial approach to fractions in both countries is quite different. We will focus our analysis on this fraction initial approach - whose structuring elements are portrayed in Table 3 . The curricular trajectory indicates parities and contrasts between the Brazilian and the Canadian approaches that raise questions. Some of these questions are discussed below.

Fractions arise from the need to register quantities smaller than the unit. However, they also register quantities greater than 1 . The Brazilian dimension of the curricular trajectory shows the introduction of fractions, in grade 3, starting from halves and thirds, followed by unit fractions in grade 4 , and fractions in general in grades 5 and 6 (see Table 3). In other words, the Brazilian document recommends the approach based on unitary fractions, without suggesting the differentiation between proper and improper fractions. A fraction could be expressed by the "sum" of unit fractions, as proposed in [23], for example. The Canadian dimension, on the other hand, recommends starting the teaching of fractions by proper fractions, in grades 3, 4 and 5. Improper fractions are addressed in grade 6 (see Table 3). The nominal difference for fractions smaller and larger than the unit is not even highlighted in the Brazilian document. Hence, at least one contrast is in evidence and raises the question: "Why or why not differentiate between proper and improper fractions in the teaching of fractions?"

The part/whole construct is strongly associated with the teaching of fractions [24]. The analysis of the curricular trajectory points to a contrast that leads to a reflection on when such a concept should be discussed. The BNCC explicitly proposes this discussion, in grade 5, two years after the beginning of the teaching of fractions (see Table 3). The CCF, on the other hand, brings the part/whole construct in the first year of teaching about fractions, in grade 3 (see Table 3). This observation is associated with another question that is intrinsic to the knowledge of mathematics for teaching: "What is the relevance of and the relationship between the part-whole construct and the other constructs associated with fractions?" For Behr and his collaborators, as the scheme shown in Figure 4 illustrates, the concept of fractions involves five distinct but interrelated constructs: Part/Whole, Ratio, Operator, Quotient and Measure. From this perspective, the part/whole construct has a primary value, being fundamental for the composition of the other meanings attributed to fractions. Regardless of its relevance, it is up to the teacher to ensure that it does not overlap with others. Learning fractions should address all five constructs. It should be noted that the Brazilian curriculum document only proposes two of these constructs (part/whole and quotient) in grades 5 and 6 (see Table 3). The Canadian document highlights only the part/whole construct in grades 3 and 4 (see Table 3), although it deals with ratios in grade 6 and alludes to fractions in the achievement indicators; "Express a given ratio in multiple forms, such as $3: 5, \frac{3}{5}$, or 3 to 5 " [6] (p.111).

Equivalence is certainly another elementary theme in the construction of the concept of fractions. However, it is not an easy concept, it requires 
abstraction. It requires understanding that one same quantity, related to a given unit, can have different representations.

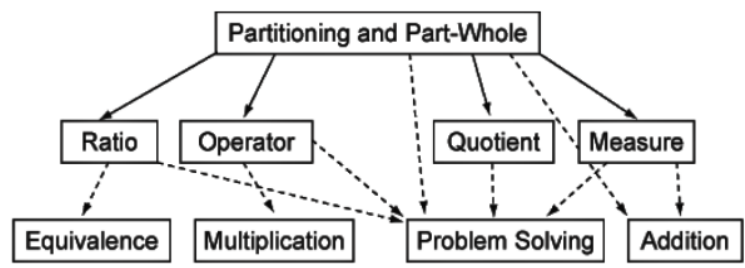

Figure 4. A conceptual scheme for instruction on rational numbers [24] (p. 100)

We could ask, "At what schooling stage should this notion of equivalence be introduced?". The curricular trajectory indicates that both the curricular guidelines from Brazil and Canada propose this introduction at grade 5, two years after the introduction of the concept of fractions (see Table 3). However, if the structuring elements of the curricular documents are examined in greater depth, we can see that this parity has the potential to promote reflections inherent to teachers' knowledge. The BNCC presents equivalence as a grade 5 skill and associates it to the comparison and ordering of fractions (see Table 3). A CCF specific outcome also deals with this association; however, it highlights the need for students to understand that equivalent fractions belong to a set of fractions that represent the same amount (see Table 3). Certainly, this is a learning objective.

Likewise the equivalent fractions approach, the teaching of comparison and ordering of fractions can be questioned. When looking at the curricular trajectory, we notice that the CCF suggests the comparison of fractions in grade 3, together with the initial approach to fractions (see Table 3). This discussion is expanded in grade 4 and includes ordering as well. Both contents are discussed until grade 5 in the Canadian guidelines. On the other hand, the BNCC suggests the introduction of comparison and ordering of fractions in grades 5 and 6, together with the study of equivalent fractions (see Table 3 ). It is evident that there is a mismatch between the two curricular guidelines when it comes to the starting point of the teaching of comparison and ordering of fractions: grade 3 in the $\mathrm{CCF}$ and grade 5 in the BNCC. In addition to this chronological mismatch, we can also ask: "What is the potential contribution or limitation of the teaching of comparison and ordering of fractions linked to the equivalence of fractions?" It is possible, and it should be expected, that a student decides, for example, that $1 / 6$ is greater than $1 / 8$ just by observing the equipartition of the unit. This result can support the recognition that $5 / 6$ is, therefore, greater than $5 / 8$. It can also be observed (with or without the support of visual representation) that $5 / 6$ is smaller than $7 / 8$ since the former lacks $1 / 6$ to complete the unit and the latter $1 / 8$ (which is smaller than $1 / 6$ ).
Without disregarding the relevance of equivalence to the development of the processes of comparison and ordering of fractions, procedures such as those described above certainly contribute to the development of less mechanized reasoning.

Another aspect that can be analyzed is the introduction of basic operations (addition, subtraction, multiplication, and division) involving fractions. The BNCC determines that the teaching of addition and subtraction of fractions should begin at grade 6 (see Table 3 ). The CCF does not mention this content on or before grade 6 (see Table 3 ). It is also observed that none of the documents proposes the teaching of multiplication and division of fractions in the period analyzed. The reflection is immediate: " $A t$ what schooling stage should the teaching of basic operations involving fractions begin?". It is worth questioning what cognitive demands each of these operations imposes [25]. For example, Son [25], based on the observation of problems proposed in textbooks and curriculum guidelines from Korea and the USA, examines the opportunities for learning the addition and subtraction of fractions at the grade school level grounded on students' cognition. It is a fact that the addition and subtraction of fractions can be supported by the conceptual understanding of these operations in the context of whole numbers: joining, separating, and comparing [17] [26]. However, this conceptual extension does not match the calculation procedures. It is necessary to understand how to add (or subtract) fractions with the same denominators and with different denominators. Inquiries like these can lead to reflections about student's cognitive and abstract development when it comes to fractions, and to reflections about the teaching of fractions and its curricular distribution.

By observing the curricular trajectory, other questions may emerge when seeking to extrapolate the teaching of fractions and relating it to other content specific to the teaching of rational numbers. For example, we observe that the Brazilian document proposes the relationship between fractions and decimal representation only in grade 6 (see Figure 2). The Canadian document, in contrast, proposes this relationship in grade 4 (see Figure 2). Still on rational numbers, the curricular trajectory reveals that the teaching of percentage starts in Brazil in grade 5, while in Canada only in grade 6 (see Figure 2); however, the curricular trajectory does not identify which representations (percentual, fractional, decimal) are explored and how such representations should be related. The analysis of the curricular trajectory also enables questions beyond the teaching of rational numbers. We observe, for example, that the number line is explored across all number sets addressed from grade 1 to grade 6 . The number line supports the teaching of whole numbers, rational numbers, and integers (in the case of the Canadian curriculum guidelines). Particularly, it is worth 
exploring the role of the number line in the teaching and learning of fractions. Investigating and understanding the underpinnings behind the different approaches discussed above can potentially promote new reflections, studies, questionings, and developments on the teaching of numbers, especially in what concerns teachers' practice.

Table 3. Structuring elements - fractions

\begin{tabular}{|c|c|c|}
\hline & BNCC [5] & $\mathrm{CCF}[6]$ \\
\hline $\begin{array}{l}G \\
R \\
A \\
D \\
E\end{array}$ & $\begin{array}{l}\text { Skills } \\
\text { (EF03MA09) Associate the quotient of a division with } \\
\text { zero remainder of a natural number by } 2,3,4,5 \text { and } 10 \text { to } \\
\text { the ideas of halves, thirds, fourths, fifths and tenths. (p. } \\
287 \text { ) }\end{array}$ & $\begin{array}{l}\text { Specific Outcome } \\
\text { 13. Demonstrate an understanding of fractions by: } \\
\checkmark \text { explaining that a fraction represents a part of a } \\
\text { whole } \\
\checkmark \text { describing situations in which fractions are used } \\
\checkmark \text { comparing fractions of the same whole with like } \\
\quad \text { denominators. (p. 78) }\end{array}$ \\
\hline $\begin{array}{l}G \\
R \\
A \\
D \\
E\end{array}$ & $\begin{array}{l}\text { Skills } \\
\text { (EF04MA09) Recognize the most common unit fractions } \\
(1 / 2,1 / 3,1 / 4,1 / 5,1 / 10 \text { and 1/100) as measurement units } \\
\text { smaller than one unit, using the number line as a resource. } \\
\text { (p. 291) }\end{array}$ & $\begin{array}{l}\text { Specific Outcome } \\
8 \text {. Demonstrate an understanding of fractions less than or } \\
\text { equal to one by using concrete and pictorial } \\
\text { representations to: } \\
\checkmark \text { name and record fractions for the parts of a whole or } \\
\text { a set } \\
\checkmark \text { compare and order fractions } \\
\checkmark \text { model and explain that for different wholes, two } \\
\text { identical fractions may not represent the same } \\
\text { quantity } \\
\text { provide examples of where fractions are used. (p. } \\
\text { 89) }\end{array}$ \\
\hline $\begin{array}{l}G \\
R \\
A \\
D \\
E\end{array}$ & $\begin{array}{l}\text { Skills } \\
\text { (EF05MA03) Identify and represent fractions (smaller } \\
\text { and larger than unity), associating them to the result of a } \\
\text { division or to the idea of part of a whole, using the number } \\
\text { line as a resource. (p. 295) } \\
\text { (EF05MA04) Identify equivalent fractions. (p. 295) } \\
\text { (EF05MA05) Compare and order positive rational } \\
\text { numbers (fractional and decimal representations), } \\
\text { relating them to points on the number line. (p. 295) }\end{array}$ & $\begin{array}{l}\text { Specific Outcome } \\
\text { 7. Demonstrate an understanding of fractions by using } \\
\text { concrete and pictorial representations to: } \\
\checkmark \text { create sets of equivalent fractions } \\
\checkmark \text { compare fractions with like and unlike } \\
\text { denominators. (p. 99) }\end{array}$ \\
\hline $\begin{array}{l}G \\
R \\
A \\
D \\
E\end{array}$ & $\begin{array}{l}\text { Skills } \\
\text { (EF06MA07) Understand, compare and order fractions } \\
\text { associated with the ideas of parts of integers and the result } \\
\text { of a division, identifying equivalent fractions. (p. 301) } \\
\text { (EF06MA08) Recognize that positive rational numbers } \\
\text { can be expressed in fractional and decimal forms, } \\
\text { establish relationships between these representations, } \\
\text { moving from one representation to another, and relate } \\
\text { them to points on the number line. (p. 301) } \\
\text { (EF06MA09) Solve and elaborate problems involving the } \\
\text { calculation of the fraction of a quantity and whose result } \\
\text { is a whole number, with and without the use of a } \\
\text { calculator. (p. 301) } \\
\text { (EF06MA10) Solve and elaborate problems involving } \\
\text { addition or subtraction with positive rational numbers in } \\
\text { the fractional representation. (p. } 301 \text { ) }\end{array}$ & $\frac{\text { Specific Outcome }}{\text { 4. Relate improper fractions to mixed numbers. (p. 110) }}$ \\
\hline
\end{tabular}




\section{Conclusion}

"Research that looks across countries can provide a sharper picture of what matters in instruction aimed at developing [mathematical] proficiency" [17] (p. 358). We argue that relating broad-reaching curricular references, such as the BNCC [5] and the CCF [6], can contribute (i) to the evaluation and development of such curricular references, (ii) to the development of materials and textbooks, and (iii) to guide teachers' training and practice. Ultimately, focused on improving students' mathematical learning. In this sense, this study, which focuses on the teaching of numbers, proposes a reflective discussion led by questions about the teaching of fractions. The underlined issues are based on the observation of the curricular trajectory - a multidimensional graphic scheme, product of this study, that organizes curricular emerging parities and contrasts, grounded on the combined reading of Brazilian and Canadian curricular documents.

The curricular trajectory surpasses its conclusive nature and offers reflections that have the potential to unfold new research questions and developments of this study. We understand that the curricular trajectory can be appreciated as a vertex of a graph. One can look backward, seeking to deepen several issues that, even though were observed in this study, are not evident in the direct reading of the infographic. Or one can look forward, raising new questions, pointing to or inspiring future studies, or even serving as a reference to support various investigations. The curricular trajectory can also extrapolate its original focus on the intended curriculum and contribute to research investigations focused on the implemented curriculum. In other words, the curricular trajectory can foster not only curriculum-related analysis, but also didactic-pedagogical discussions, and the investigation of textbooks or other teaching materials. Such a change in focus enables a shift from the intended to the implemented curriculum, further contributing to curricular discussions in the mathematics education community.

\section{References}

[1] Li, Y. and Lappan, G. (2014) Mathematics Curriculum in School Education, Springer, Netherlands.

[2] Shimizu, Y. and Vithal, R. (2018) School Mathematics Curriculum Reforms: Challenges, Changes and Opportunities, University of Tsukuba, Tsukuba.

[3] Ball, D., Thames, M. H. and Phelps, G. (2008) "Content knowledge for teaching: What makes it special?", Journal of Teacher Education, 59(5), pp. 389-407.

[4] UNESCO (2016) Glossary of Curriculum Terminology, UNESCO International Bureau of Education, Paris.
[5] Brasil (2017) Base Nacional Comum Curricular, Ministério da Educação, Brazil.

[6] Alberta Education (2006) The Common Curricular Framework for K-9 Mathematics, Alberta Education, Alberta.

[7] Garnica, A. V. M. (2014) "Brief Considerations on Educational Directives and Public Policies in Brazil Regarding Mathematics Education", Mathematics Curriculum in School Education, 1, pp. 143-156.

[8] Suurtamm, C., Huntley, M. A. and Thompson, D. R. (2018) International Perspectives on Mathematics Curriculum, Information Age Publishing Inc., North Carolina.

[9] Macedo, E. (2006) "Currículo: Política, Cultura e Poder”, Currículo sem Fronteiras, 6(2), pp. 98-113.

[10] Gomes, N. L. (2012) "Relações Étnico-Raciais, Educação e Descolonização dos Currículos", Currículo sem Fronteiras, 12(1), pp. 98-109.

[11] Berry, J. (2009) "Can There Be an Alternative to the Centralized Curriculum in England?", Improving Schools, 12(1), pp. 33-41.

[12] Aoki, T. (1986) "Teaching as In-dwelling Between Two Curriculum Worlds", The B.C. Teacher, Vancouver, 65(3).

[13] Valverde, G., Bianchi, L. J., Wolfe, R. G., Schmidt, W. H. and Houang, R. T. (2002) "Textbooks and Educational Opportunity", in According to the Book, Springer Science + Business Media: New York, pp. 1-20.

[14] Rojano, T. and Solares-Rojas, A. (2018) "The mathematics curriculum design from an international perspective: methodological elements for a comparative analysis", in School Mathematics Curriculum Reforms: Challenges, Changes and Opportunities, University of Tsukuba: Tsukuba, pp. 475-482.

[15] OECD (2013) PISA 2012 Assessment and Analytical Framework: Mathematics, Reading, Science, Problem Solving and Financial Literacy, OECD, Paris.

[16] Simmt, E. (2017) "Curriculum in Canada: A Fractal Interpretation Using the Case of Alberta", in International Perspectives on Mathematics Curriculum, Information Age Publishing, pp. 103-130.

[17] Kilpatrick, J., Swafford, J. and Findell, B. (2001). Adding it up: Helping children learn mathematics, National Academy Press, Washington, DC.

[18] Sharma, S. (2013) "Qualitative Approaches in Mathematics Education Research: Challenges and Possible Solutions", Education Journal, 2(2), pp. 50-57.

[19] Zanette, M. (2017) "Qualitative research in the context of Education in Brazil", Educar em Revista, 65, pp. 149166. 
[20] Schubring, G. (2014) “A Matemática Elementar de um Ponto de Vista Superior: Felix Klein e a Sua Atualidade", in O Saber do Professor de Matemática: Ultrapassando a Dicotomia entre Didática e Conteúdo, Ciência Moderna: Rio de Janeiro, pp. 39-54.

[21] Kilpatrick, J. (2008) "The Mathematics Teacher and Curriculum Change”, PNA, 3(3), pp. 107-121.

[22] Shulman, L. S. (1986) "Those who understand: Knowledge growth in teaching", Educational Researcher, 15(2), 4-14.

[23] Wu, H. (2011) Understanding numbers in elementary school mathematics, American Mathematical Society Providence, RI.

[24] Behr, M. J., Lesh, R., Post, T.R. and Silver, E.A. (1983) "Rational number concepts", in Acquisition of mathematics concepts and processes, Academic Press: New York, pp. 91126.

[25] Son, J. W. (2012) "A cross-national comparison of reform curricula in Korea and the US in terms of cognitive complexity: the case of fraction addition and subtraction", ZDM Mathematics Education, 44, pp. 161-174.

[26] Van de Walle, J. A., Karp, K. S. and Bay-Williams, J. M. (2009) Elementary and middle school mathematics: Teaching developmentally (7th ed.), Pearson Education, Boston. 